\title{
A Novel Numerical Algorithm for Optimal Sizing of a Photovoltaic/Wind/Diesel Generator/Battery Microgrid Using Loss of Load Probability Index
}

\author{
Hussein A. Kazem and Tamer Khatib \\ Faculty of Engineering, Sohar University, P.O. Box 44, 311 Sohar, Oman \\ Correspondence should be addressed to Tamer Khatib; tamer_khat@hotmail.com
}

Received 26 January 2013; Accepted 30 March 2013

Academic Editor: David Lee Phillips

Copyright ( $\odot 2013$ H. A. Kazem and T. Khatib. This is an open access article distributed under the Creative Commons Attribution License, which permits unrestricted use, distribution, and reproduction in any medium, provided the original work is properly cited.

\begin{abstract}
This paper presents a method for determining optimal sizes of PV array, wind turbine, diesel generator, and storage battery installed in a building integrated system. The objective of the proposed optimization is to design the system that can supply a building load demand at minimum cost and maximum availability. The mathematical models for the system components as well as meteorological variables such as solar energy, temperature, and wind speed are employed for this purpose. Moreover, the results showed that the optimum sizing ratios (the daily energy generated by the source to the daily energy demand) for the PV array, wind turbine, diesel generator, and battery for a system located in Sohar, Oman, are $0.737,0.46,0.22$, and 0.17 , respectively. A case study represented by a system consisting of $30 \mathrm{kWp} \mathrm{PV}$ array (36\%), $18 \mathrm{kWp}$ wind farm (55\%), and $5 \mathrm{kVA}$ diesel generator (9\%) is presented. This system is supposed to power a $200 \mathrm{kWh} /$ day load demand. It is found that the generated energy share of the PV array, wind farm, and diesel generator is $36 \%, 55 \%$, and $9 \%$, respectively, while the cost of energy is $0.17 \mathrm{USD} / \mathrm{kWh}$.
\end{abstract}

\section{Introduction}

Hybrid photovoltaic (PV)/wind/diesel power generating system installation has played an important role due to the fact that the system is clean, environment friendly, and a secure energy source. Currently, some research works are carried out focusing on optimization of hybrid PV/wind/diesel power generating system so that the capacity of PV array, wind turbine, diesel generator, and storage battery capacity can be optimally selected [1-6]. The hybrid PV/wind/diesel power generating system size and performance strongly depend on metrological variables such as solar energy, ambient temperature, and wind speed, and therefore, to optimize the system, extensive studies related to metrological variables have to be done [1]. Optimization works related to hybrid $\mathrm{PV} /$ wind/diesel system can be found in the literature [1$6]$. In $[2,3]$, hourly meteorological variables such as wind speed, solar energy, and ambient temperature for specific locations in Saudi Arabia are used to design a PV/wind/ diesel generator system. Intuitive mathematical relations have been developed to design the hybrid system but without any optimization.

The application of advanced optimization techniques for designing hybrid PV/wind/diesel systems can be found in $[4-6]$. In $[4,5]$, the Strength Pareto evolutionary algorithm is used to optimize a PV/wind/diesel generator system by formulating a two objective optimization problem. The objectives are to minimize system cost and pollutant emissions. The mathematical models of the energy sources included in the hybrid PV/wind/diesel system and the hourly meteorological data are used in designing the system. In [6], an iterative method and evolutionary algorithm are applied to optimize a hybrid PV/wind/diesel generating system. Here, a possible design space for the assumed load demand is first configured, and then an iterative method as well as evolutionary algorithm is used to determine the optimum configuration among the design space configurations. The generated design space contains over 6 million possible configurations. It is found that the evolutionary algorithm is faster than the iterative method in finding the optimum 


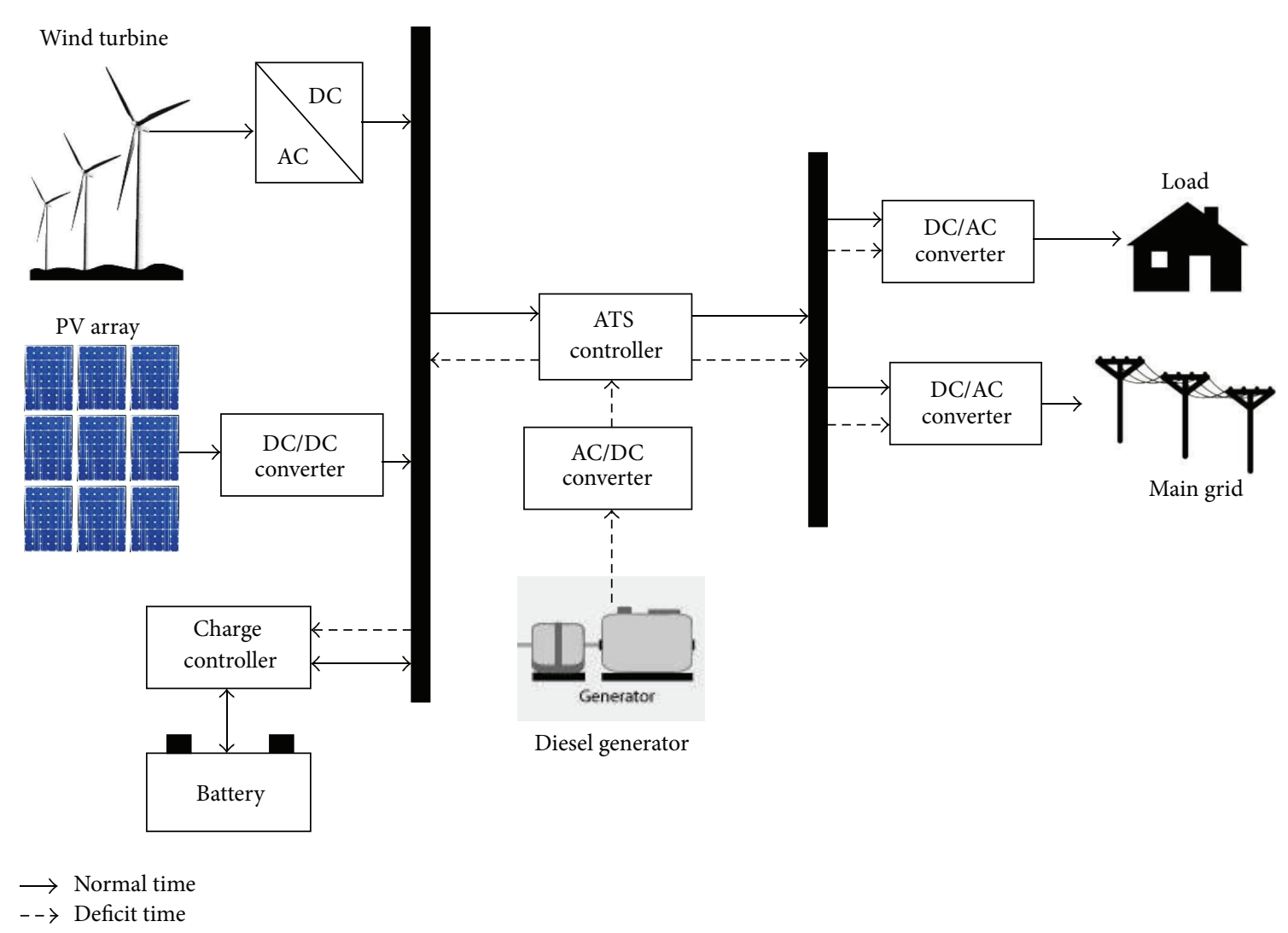

FIGURE 1: Building integrated hybrid PV/wind/diesel generating system.

design space configuration [6]. However, in this optimization method, the availability of the hybrid system configuration which has availability values in the range of $0-100 \%$ is not considered, and this results in a large size of the design space. If a specific availability level is considered, the size of the design space would have been significantly reduced. In addition, actual values of equipment have been used thus making the results limited to the assumed load demand. By using a defined sizing ratio, the method is not case specific and applicable for any load demand. Finally, in [79], the HOMER software has been used to optimally size hybrid PV/wind/diesel generating systems by considering the weather profile of Malaysia.

In this paper, a novel optimization method taking into consideration the maximum availability and the minimum system capital cost has been developed for optimal sizing of a building integrated PV/wind/diesel generating system. To evaluate the effectiveness and accuracy of the proposed optimization method, it is compared with the method employed in the HOMER software. The meteorological data for Sohar provided by Sohar University has been used in this work.

\section{Modeling of Energy Sources in the Hybrid PV/Wind/Diesel Generating System}

The proposed building integrated multigenerator system consisting of PV array, wind turbine, battery storage, and diesel generator as the main energy sources is shown in Figure 1. The system is designed to supply a building load while the excess energy will be injected to the grid. The building load is mainly supplied by the PV array and the wind turbine. When the energy produced by the PV array and the wind turbine, is not sufficient to fulfill the load demand, the battery will cover the energy deficit. However, in case that the energy produced by the PV array, wind turbine, and the battery is not able to meet the load demand, the diesel generator will cover the remaining load and charge the battery until reaching its maximum state of charge.

The energy produced by a PV module can be calculated in terms of solar energy and ambient temperature, and it can be expressed as

$$
E_{\mathrm{PV}}(t)=A_{\mathrm{PV}} E_{\mathrm{sun}}(t) \eta_{\mathrm{PV}}(t) \eta_{\mathrm{INV}} \eta_{\mathrm{WIRE}}
$$

where $A_{\mathrm{PV}}, E_{\text {sun }}, \eta_{\mathrm{PV}}, \eta_{\mathrm{INV}}$, and $\eta_{\mathrm{WIRE}}$ are the area of PV array, solar energy, PV module conversion efficiency, inverter conversion efficiency, and wire efficiency, respectively.

However, the effect of temperature on the conversion efficiency of a PV module can be expressed as

$$
\eta_{\mathrm{PV}}(t)=\eta_{\mathrm{PV}_{\mathrm{ref}}}\left[1-\beta\left(T_{C}(t)-T_{C_{\mathrm{ref}}}\right)\right]
$$




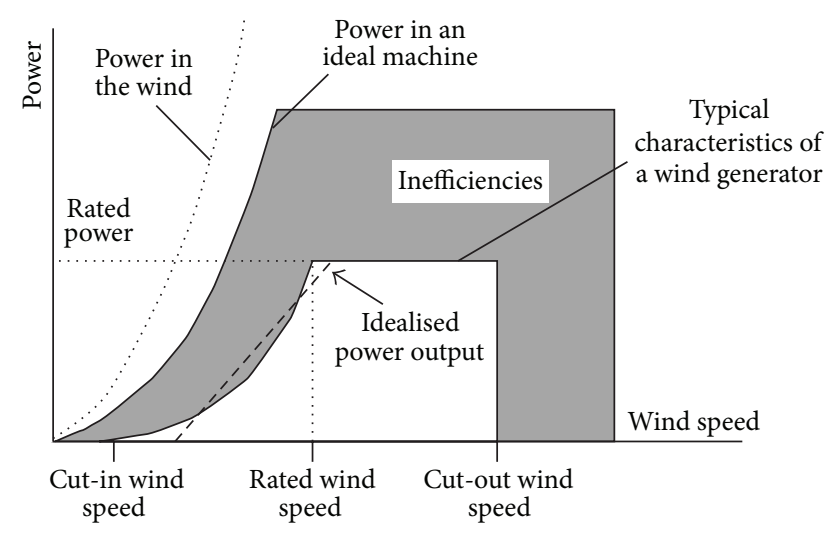

Figure 2: A wind turbine characteristic [10].

where $\eta_{\mathrm{PV}_{\text {ref }}}, \beta, T_{C}$, and $T_{C_{\text {ref }}}$, are the reference $\mathrm{PV}$ module conversion efficiency, temperature coefficient for the efficiency, cell temperature, and reference cell temperature, respectively.

The cell temperature is calculated using the ambient temperature as follows:

$$
T_{C}(t)-T_{\text {ambient }}=\frac{T_{\text {Test }}}{800} G(t),
$$

where $T_{\text {ambient }}, T_{\text {Test }}$, and $G$ are the ambient temperature, temperature during testing the PV module, and solar radiation, respectively.

As for the wind generator, its output power is a function of wind speed as illustrated in Figure 2.

From Figure 2, the wind turbine characteristic can be described as follows:

$$
\left\{\begin{array}{ll}
0, & V_{\text {cut out }}<V<V_{\text {cut in }} \\
P_{\text {rated }}, & V=V_{\text {rated }} \\
P=c_{1} e^{c_{2} V}+c_{3} e^{c_{4} V}, & V_{\text {cut in }}<V<V_{\text {rated }}
\end{array}\right\} .
$$

The coefficients $c_{1}-c_{4}$ can be calculated by using a curve fitting tool such as the MATLAB fitting tool. However, this model is not suitable to be used in an iterative loop with a small step, and therefore, in this research work, the output energy of a wind turbine is done using the wind kinetic energy.

The wind turbine output energy depends on the amount of wind power which hits the blades of a wind turbine. As wind is made up of moving molecules which have mass, wind energy is in terms of its kinetic energy, and it is given by

$$
\text { Kinetic energy }=\frac{1}{2} M V^{2},
$$

where $M$ is the mass of wind molecules $(\mathrm{kg})$ and $V$ is the wind speed $(\mathrm{m} / \mathrm{s})$.

Considering that air has a known density of about $1.23 \mathrm{~kg} / \mathrm{m}^{3}$, the mass which hits a wind turbine with a swept area at each second is given by

$$
\frac{M}{S}=V\left(\frac{\mathrm{m}}{\mathrm{s}}\right) A_{W}\left(\mathrm{~m}^{2}\right) \text { Air density }\left(\frac{\mathrm{Kg}}{\mathrm{m}^{3}}\right),
$$

where $A_{W}$ is wind turbine swept area.
Substituting (5) into (6), the power of the wind hitting a wind turbine with a certain swept area is given by

$$
P_{W}=\frac{1}{2} \text { Air density } r^{2} \pi V^{3}
$$

where $r$ is wind turbine rotor radius.

The output energy of wind turbine $\left(E_{W}\right)$ is then calculated as follows:

$$
E_{W}=24 P_{W} \eta_{W}
$$

where $\eta_{W}$ is the conversion efficiency of a wind turbine.

As for the diesel generator, the output energy can be calculated as follows:

$$
E_{D}=\text { rated power } * \text { operation hours. }
$$

Here, it is assumed that the diesel generator reaches its rated power shortly after it starts operating.

\section{Proposed Optimization Algorithm}

The proposed optimization algorithm used for optimal sizing of the hybrid PV/wind/diesel generating system is divided into three phases. In the first phase, a design space for the system is generated as shown in Figure 3. The phase starts by defining specification of the energy sources such as the energy conversion efficiencies, PV module area, and temperature coefficient for PV module conversion efficiency, unit costs, load demand, availability level, and metrological data such as solar energy, wind speed, and ambient temperature. The initial values of the sizes for the PV array, wind turbine, and diesel generator are set. The output energy for each size of these energy sources is calculated using the models described in the previous section. Then, the main energy difference which is the difference in energy at the front end of the system and energy at the load side is given by

$$
E_{D}(t)=\sum_{i=1}^{8670}\left(E_{T}(t)-E_{L}(t)\right),
$$

where $E_{T}$ and $E_{L}$ are the total energy produced and the load energy demand, respectively.

The result of (10) is that it may be either positive $\left(E_{T}>\right.$ $\left.E_{L}\right)$ or negative $\left(E_{T}<E_{L}\right)$. If the energy difference is positive then there is excess in energy, while if it is negative then there will be energy deficit. The excess energy is stored in batteries in order to be used in case of energy deficit. Meanwhile, energy deficit can be defined as the disability of the energy sources to provide power to the load at a specific time. Therefore, the energy flow across the battery can be expressed as

$$
\begin{aligned}
& E_{\text {Battery }}(t) \\
& =\left\{\begin{array}{ll}
E_{\text {Battery }}(t-1) * \eta_{\text {inv }} * \eta_{\text {wire }} * \eta_{\text {discharging }}-E_{L}(t) & E_{D}<0 \\
E_{\text {Battery }}(t-1) * \eta_{\text {charging }}+E_{T}(t) & E_{D}>0 \\
E_{\text {Battery }}(t-1) & E_{D}=0
\end{array}\right\} .
\end{aligned}
$$




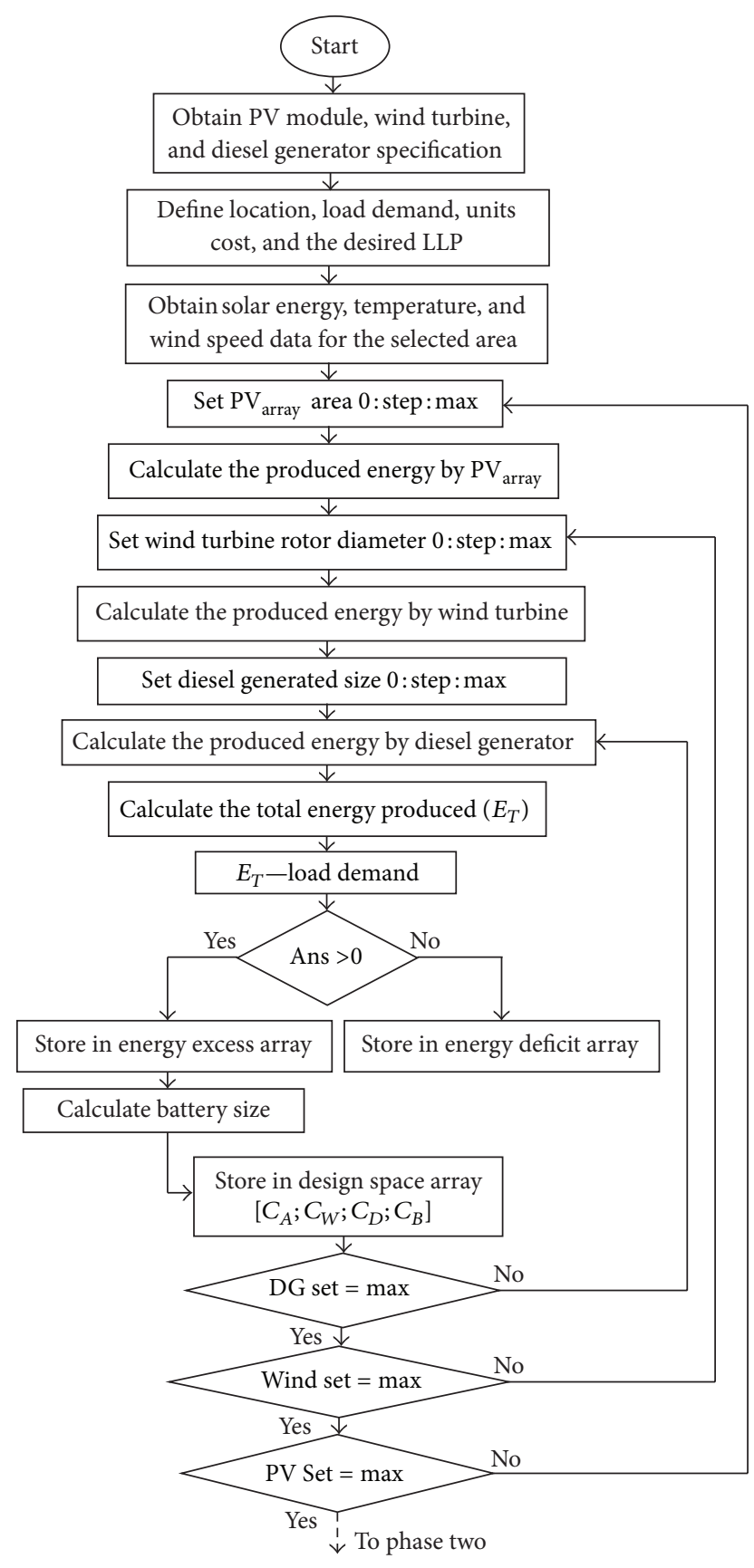

FIGURE 3: The first phase of the proposed optimization algorithm.

The battery size $\left(E_{B}\right)$ is estimated using the excess energy, and it is expressed as

$$
E_{B}=\frac{\sum_{i=0}^{8750} \text { Excess enery } g_{i} * \eta_{B}}{V_{B}},
$$

where $\eta_{B}$ and $V_{B}$ are the charging efficiency and the battery voltage, respectively.

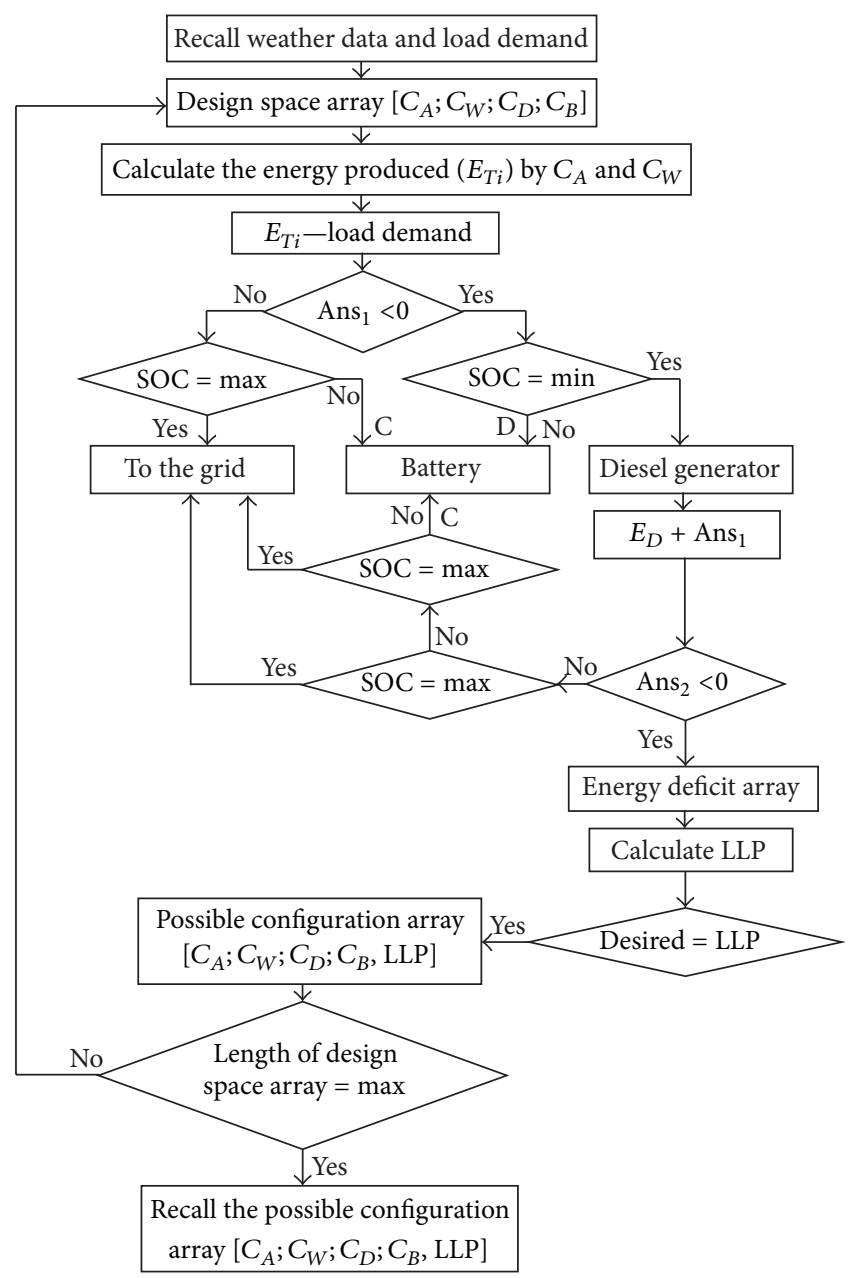

FIGURE 4: The second phase of the proposed optimization algorithm.

To generalize the optimization results, the following parameters are defined:

$$
\begin{aligned}
& C_{A}=\frac{E_{\mathrm{PV}_{\text {daily }}}}{\operatorname{Load}_{\text {daily }}}, \\
& C_{W}=\frac{E_{W_{\text {daily }}}}{\operatorname{Load}_{\text {daily }}}, \\
& C_{D}=\frac{E_{D_{\text {daily }}}}{\operatorname{Load}_{\text {daily }}}, \\
& C_{B}=\frac{E_{B_{\text {daily }}}}{\operatorname{Load}_{\text {daily }}},
\end{aligned}
$$

where the numerator term in (13) implies the daily energy produced by the energy source and the denominator is the daily energy of the load.

In the second phase of the optimization algorithm as illustrated in Figure 4, the generated design space is used to perform a simulation of the system in order to calculate the availability level of the system. In this phase, the total output 
power which is generated by the PV array and the wind turbine is calculated. Then the energy balance is examined by subtracting the load demand from the generated power. At this point, if the energy balance is negative (the generated power is not able to cover the load demand), the battery state of charge (SOC) is checked to find out whether the battery is able to supply energy or not. If the battery SOC is higher than its minimum value, then the battery is supposed to supply the remaining load demand subject to not reaching the allowable minimum SOC. On the other hand, if the battery is not able to supply the load ( $\mathrm{SOC}=\mathrm{Min})$, the diesel generator is operated to cover the remaining load and to charge the battery. However, if both the battery and diesel generator are not able to cover the remaining load demand, this energy is classified as energy deficit. This procedure is done for each hourly load demand for a duration of one year, and at the end of the year, the total energy generated by PV, wind turbine, and diesel generator is calculated. In addition, the total energy deficit is calculated in order to calculate the loss of load probability. This loop is repeated till reaching the maximum length of the design space array. Finally, all the system configurations that investigate the desired availability level are stored in an array called as the possible configuration area (Figure 4).

In designing the proposed system, it is important to know the power supply availability. $100 \%$ availability of power supply means that the power supply is able to cover load demand in a year without any interruption. On the other hand, $0 \%$ availability of power supply means that the power supply is not able to cover load demand in a year at all. This means that high system availability leads to high reliability and vice versa. However, high reliability systems incur high initial cost, and therefore, it is not feasible to design systems with very high availability rates. The availability of a proposed system is expressed in a statistical value which is the loss of load probability (LLP). LLP is the ratio of annual energy deficits to annual load demand, and it is given by

$$
\text { LLP }=\frac{\sum_{i=1}^{366} \text { Energy deficits }_{i}}{\sum_{j=1}^{366} \text { Energy demand }_{j}} .
$$

In the third phase of the optimization, the unit costs are defined for each component in the systems, and the system cost is calculated. The system cost includes the capital, running, and replacement costs. Finally, the system with minimum cost is considered as the optimum system.

\section{Test Results}

Optimization of the building integrated hybrid PV/wind/ diesel generating system for Sohar, Oman, has been conducted by considering the average hourly solar energy and wind speed which are in the range of $4.5-5.2 \mathrm{kWh} / \mathrm{m}^{2}$ and $1.3-5.1 \mathrm{~m} / \mathrm{s}$, respectively. For feasibility of installing the hybrid PV/wind/diesel generating system, the sites must have acceptable average daily wind speed. Figure 5 shows the monthly averages of solar energy and wind speed for Sohar. From the figure, the annual daily average of solar energy is $5.12 \mathrm{kWh} / \mathrm{m}^{2}$ with the highest value in April and the lowest

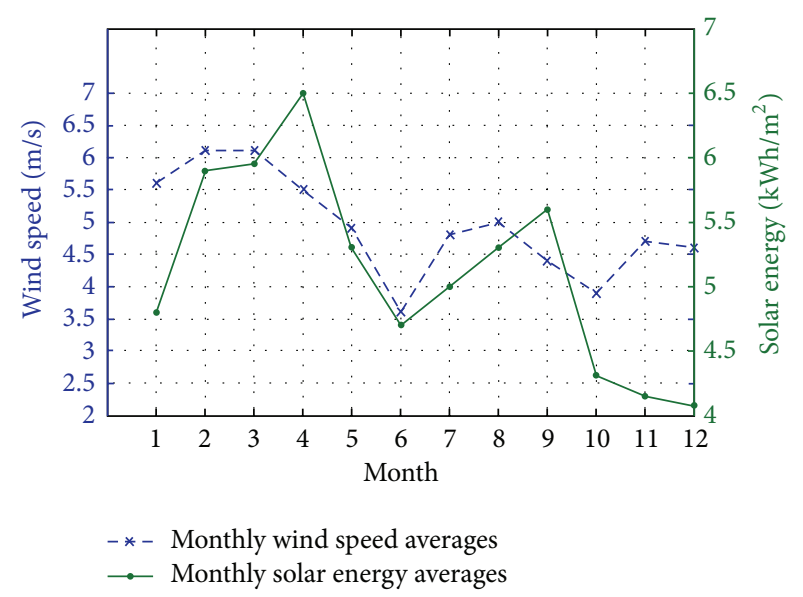

FIGURE 5: Average monthly solar energy and wind speed for Sohar.

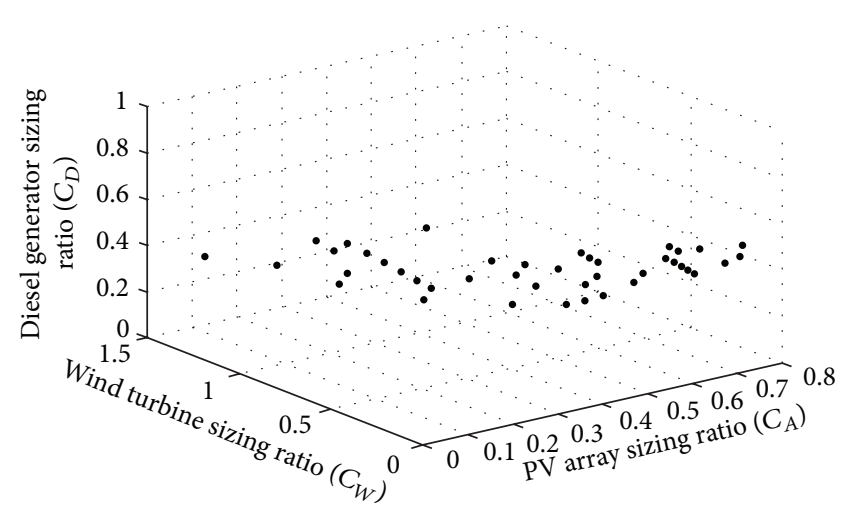

FIGURE 6: Design space for the proposed hybrid PV/wind/diesel system subject to $1 \%$ LLP.

value in December. Meanwhile, February and March have the highest wind speed, while June has the lowest wind speed. The average wind speed is $4.9 \mathrm{~m} / \mathrm{s}$.

In this research, the proposed system is supposed to supply a $200 \mathrm{kWh} /$ day (16 kW peak) to a building located in Sohar subject to 1\% LLP. Figure 6 shows the design space for the proposed system in which all the configurations are able to supply the load with $1 \%$ of LLP. Among these configurations, the optimum configuration is the one which has the minimum cost. The optimization results showed that the optimum sizing ratios $\left(C_{A}, C_{W}, C_{D}\right.$, and $\left.C_{B}\right)$ for the proposed system located in Sohar are $0.737,0.46,0.22$, and 0.17 , respectively. From these values, the system consisting of $30 \mathrm{kWp}$ PV array, $18 \mathrm{kWp}$ wind farm, $5 \mathrm{kVA}$ diesel generator at 0.85 power factor, and $2.8 \mathrm{kAh} / 12 \mathrm{~V}$ battery is recommended to supply the load demand.

Figure 7 shows the energy generation shares in the proposed system. The PV array produces $29366 \mathrm{kWh}$ per annum; meanwhile, the wind energy production is $44479 \mathrm{kWh}$ per annum. In addition, the diesel generator produces $6822 \mathrm{kWh}$ per annum. As for the battery, it is used in almost $25 \%$ of the year time. Figure 8 shows the energy that is to be sold to the grid and the energy deficit cases as well. From the figure, $7358 \mathrm{kWh}$ per annum is supposed to be sold 

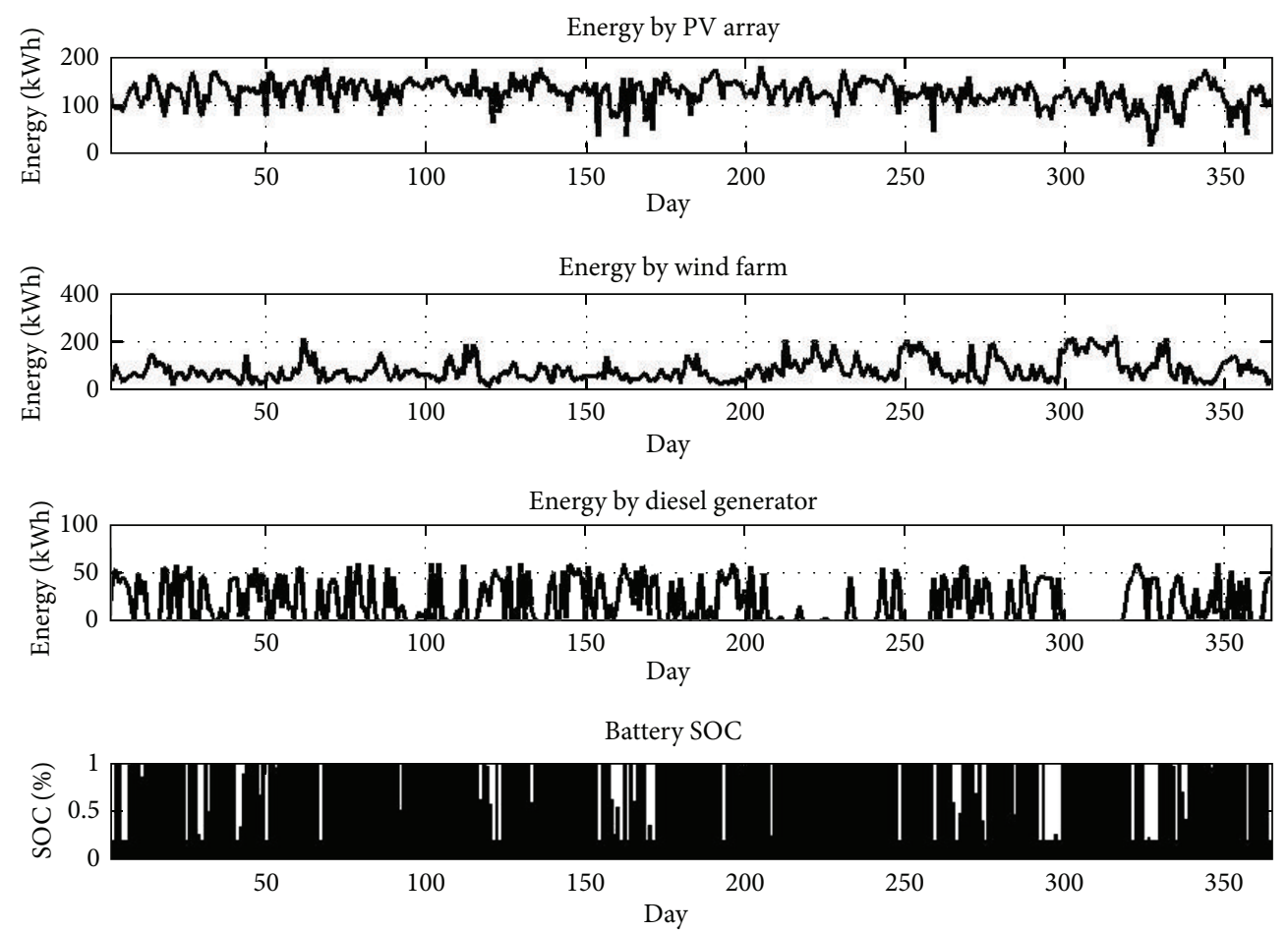

FIGURE 7: Energy generation share of the proposed system.
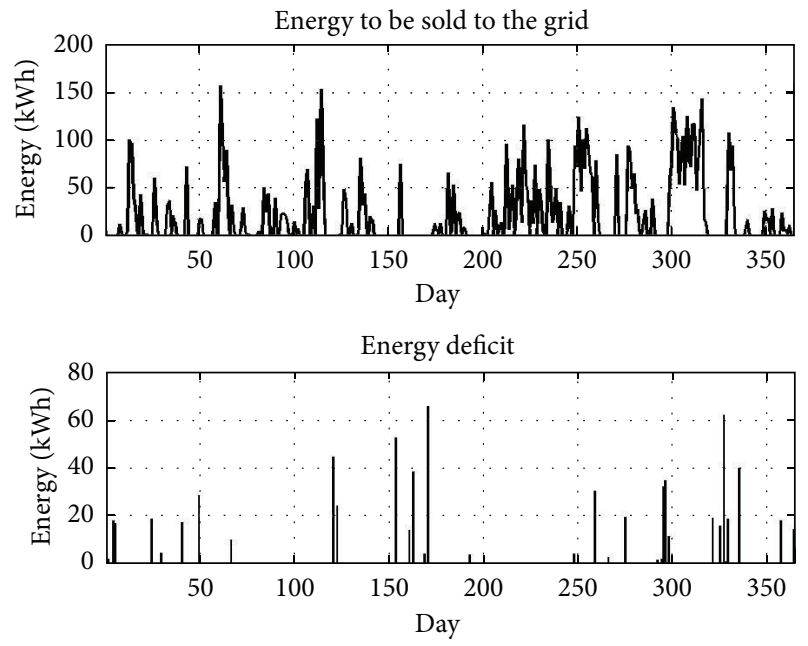

FIgURE 8: Excess and deficit energy of the proposed system.

to the grid while the energy deficit for a period of one year is $753 \mathrm{kWh}$. The energy demand of the proposed system is $73000 \mathrm{kWh} / \mathrm{annum}$, and consequently the loss of load probability of the proposed system is $1.03 \%$.

Table 1 shows the cost of the various components in the proposed system cost and the total cost of the system which is 207,228 USD. The system cost is calculated based on the cost of energy generated by the proposed system which is about $0.17 \mathrm{USD} / \mathrm{kWh}$. In Oman, the cost of energy supplied by the electric utility is $0.11 \mathrm{USD} / \mathrm{kWh}$, and this means that the approximate annual feed in tariff is 810 USD, calculated by multiplying the annual energy injected to the grid with $0.11 / \mathrm{kWh}$. While annual saving is calculated by multiplying the sum of the annual energy that is supposed to be supplied by the Omani electricity grid with the price of kWh in Oman, the approximate annual saving is found to be 8850 USD.

4.1. Comparison with the HOMER Software. The proposed optimization algorithm for determining optimal sizing and cost of the hybrid $\mathrm{PV} /$ wind/diesel generating system has been validated by comparing it with the optimization method available in the HOMER software. Figure 9 shows the designed system specification using the HOMER software in which the system consists of $36 \mathrm{kWp}$ PV array, $15 \mathrm{kWp}$ wind turbine ( $3 \mathrm{kWp}$ times 5 units), $5 \mathrm{~kW}$ diesel generator, and $3 \mathrm{kAh} / 12 \mathrm{~V}$ storage battery (500 Ah times 6 units).

From Figure 9, there is a slight difference between the energy sources capacity calculated using HOMER and the proposed optimization method. The PV array capacity of the proposed optimization method ( $30 \mathrm{kWp}$ ) is $83 \%$ of the PV array capacity calculated using HOMER $(36 \mathrm{kWp})$. Meanwhile, the wind turbine capacity calculated using HOMER $(15 \mathrm{kWp})$ is $83 \%$ of the wind turbine capacity of the proposed optimization method $(18 \mathrm{kWp})$. On the other hand, the battery capacity of the proposed optimization method $(2.8 \mathrm{kAh})$ is less by $7 \%$ than that calculated using HOMER $(3 \mathrm{kAh})$. As for the diesel generator, similar size is determined by both optimization methods. The differences in the PV, wind, and battery sizes may be due to the assumed values of the PV module and wind turbine energy conversion efficiencies, battery charging and discharging efficiencies, power conversion devices efficiencies, PV module and wind 
TABLE 1: Costs of the proposed system.

\begin{tabular}{|c|c|c|c|c|c|}
\hline Item & Unit cost $(\$)$ & Capacity/quantity & Consumption & Cost $(\$)$ & Life time years/hours \\
\hline PV modules & 3.71/Wp & $30 \mathrm{kWp}$ & - & 111,300 & 20 \\
\hline Support structure & 50/unit & 56 & - & 2,800 & 20 \\
\hline Wind turbine & $1200 / \mathrm{kWp}$ & $18 \mathrm{kWp}$ & & 21,600 & \\
\hline Generator & $3600 / \mathrm{DG}$ & 2 & - & 7,200 & 13 years \\
\hline Diesel & $0.6 / \mathrm{L}$ & $26000 \mathrm{~L}$ & $2.7 \mathrm{~L} / \mathrm{h}$ & 15,600 & - \\
\hline Engine oil & $1.4 / \mathrm{L}$ & 135 & $3.5 \mathrm{~L} / 150 \mathrm{~h}$ & 189 & - \\
\hline Diesel filter & 4.5 & 12 & - & 54 & $750 \mathrm{~h}$ \\
\hline Air filter & 35 & 3 & - & 105 & $3000 \mathrm{~h}$ \\
\hline Overhaul & 1500 & 1 & - & 1500 & $26,280 \mathrm{~h}$ \\
\hline Storage battery & 2.3/Ah & $2.8 \mathrm{kAh}$ & - & 12880 & 10 \\
\hline Charge regulator & 8000 & 1 & - & 8000 & 20 \\
\hline Inverters & 8000 & 3 & - & 24,000 & 20 \\
\hline Circuit breakers & 200 & 4 & - & 800 & 20 \\
\hline Installation materials & & - & - & 600 & - \\
\hline Civil and installation work & - & - & - & 600 & - \\
\hline Total cost & & & & 207,228 & 20 \\
\hline Scrap value & & & & $15 \%$ & \\
\hline
\end{tabular}

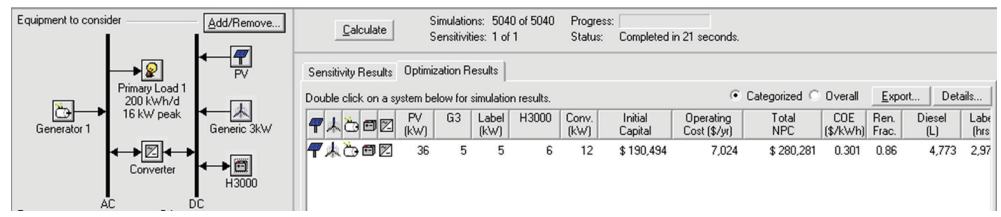

FIGURE 9: Proposed system by HOMER for the assumed load demand.

turbine unit cost, battery unit cost, diesel cost, scrap costs, and other factors such as assumed life time of the system components. However, the most important reason for the difference in energy source sizes is due the nature of the used meteorological data. The HOMER software uses the monthly average of solar energy and wind speed, and this converts it to hourly values using statistical models which may have a specific error. Meanwhile the proposed optimization method uses the daily solar energy and wind speed. From [11-16], the use of monthly meteorological data may cause over sizing or under sizing of the designed system. The advantage of the proposed optimization method is that it provides a daily simulation of the designed system performance to define the availability of the system accurately while the HOMER software does not have this capability. In addition, the proposed optimization method provides useful information about energy generation, excess energy, and exact energy deficit times of the designed system.

\section{Conclusion}

Optimization of a building-integrated PV/wind/diesel generator and battery system has been implemented using the proposed optimization method based on iterative simulation. The objective of the optimization problem is determine the optimal sizes of the PV/wind/diesel generators and battery to supply a building load demand at minimum cost and maximum availability. The mathematical models of the various system components have been developed, and the meteorological variables such as solar energy, temperature, and wind speed are used. The results showed that the optimum sizing ratio for the PV array, wind farm, diesel generator, and battery for a system located in Sohar, Oman, is $0.737,0.46,0.22$, and 0.17 , respectively. The cost of the energy produced by the proposed system is $0.17 \mathrm{USD} / \mathrm{kWh}$ while the feed in tariff of the system is $810 \mathrm{USD} /$ year. The proposed optimization method is found to give more accurate results compared to the method used in the HOMER software. The proposed optimization method can be applied for determining optimal sizes of renewable energy systems for housing electrification in Oman.

\section{Conflict of Interests}

The authors confirm that there is no conflict of interests with the developer or distributor of HOMER software. They have used the software as a part of the conducted research.

\section{Acknowledgments}

The research leading to these results has received Research Project Grant Funding from the Research Council of 
the Sultanate of Oman, Research Grant Agreement no. ORG SU EI 11 010. The authors would like to acknowledge the support from the Research Council of Oman. Gratitude is also expressed to the Faculty of Engineering and Research and Industry Collaboration Office in Sohar University.

\section{References}

[1] T. Khatib, A. Mohamed, K. Sopian, and M. Mahmoud, "Optimal sizing of building integrated hybrid PV/diesel generator system for zero load rejection for Malaysia," Energy and Buildings, vol. 43, no. 12, pp. 3430-3435, 2011.

[2] M. A. Elhadidy and S. M. Shaahid, "Parametric study of hybrid (wind + solar + diesel) power generating systems," Renewable Energy, vol. 21, no. 2, pp. 129-139, 2000.

[3] M. A. Elhadidy and S. M. Shaahid, "Promoting applications of hybrid (wind + photovoltaic + diesel + battery) power systems in hot regions," Renewable Energy, vol. 29, no. 4, pp. 517-528, 2004.

[4] J. L. Bernal-Agustín, R. Dufo-López, and D. M. Rivas-Ascaso, "Design of isolated hybrid systems minimizing costs and pollutant emissions," Renewable Energy, vol. 31, no. 14, pp. 22272244, 2006.

[5] R. Dufo-López, J. Bernal-Agustín, J. Yusta-Loyo et al., "Multiobjective optimization minimizing cost and life cycle emissions of stand-alone PV-wind-diesel systems with batteries storage," Applied Energy, vol. 88, no. 11, pp. 4033-4041, 2011.

[6] J. L. Bernal-Agustín and R. Dufo-López, "Efficient design of hybrid renewable energy systems using evolutionary algorithms," Energy Conversion and Management, vol. 50, no. 3, pp. 479-489, 2009.

[7] G. J. Dalton, D. A. Lockington, and T. E. Baldock, "Feasibility analysis of stand-alone renewable energy supply options for a large hotel," Renewable Energy, vol. 33, no. 7, pp. 1475-1490, 2008.

[8] M. Ngan and C. Tan, "Assessment of economic viability for PV/wind/diesel hybrid energy system in southern Peninsular Malaysia," Renewable and Sustainable Energy Reviews, vol. 16, no. 1, pp. 634-647, 2012.

[9] A. M. A. Haidar, P. N. John, and M. Shawal, "Optimal configuration assessment of renewable energy in Malaysia," Renewable Energy, vol. 36, no. 2, pp. 881-888, 2011.

[10] G. Boyle, Renewable Energy, OXFORD, 2004.

[11] T. Khatib, A. Mohamed, M. Mahmoud, and K. Sopian, "A review of photovoltaic systems size optimization techniques," Journal of Renewable and Sustainable Reviews, vol. 22, pp. 454-465, 2013.

[12] T. Khatib Mohamed A and K. Sopian, "Optimization of a PV/wind micro-grid for rural housing electrification using a hybrid iterative/genetic algorithm: case study of Kuala Terengganu, Malaysia," Energy and Buildings, vol. 47, pp. 321-331, 2012.

[13] A. Fragaki and T. Markvart, "Stand-alone PV system design: results using a new sizing approach," Renewable Energy, vol. 33, no. 1, pp. 162-167, 2008.

[14] T. Markvart, A. Fragaki, and J. N. Ross, "PV system sizing using observed time series of solar radiation," Solar Energy, vol. 80, no. 1, pp. 46-50, 2006.

[15] S. M. Shaahid and M. A. Elhadidy, "Prospects of autonomous/stand-alone hybrid (photo-voltaic + diesel + battery) power systems in commercial applications in hot regions," Renewable Energy, vol. 29, no. 2, pp. 165-177, 2004.
[16] S. M. Shaahid, I. El-Amin, S. Rehman et al., "Techno-economic potential of retrofitting diesel power systems with hybrid windphotovoltaic-diesel systems for off-grid electrification of remote villages of Saudi Arabia," International Journal of Green Energy, vol. 7, no. 6, pp. 632-646, 2010. 

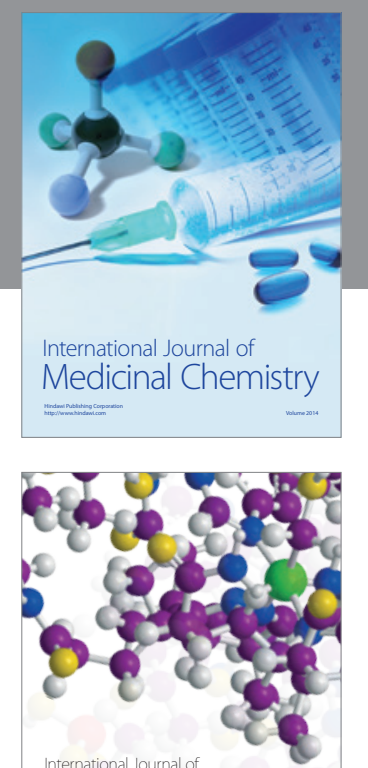

\section{Carbohydrate} Chemistry

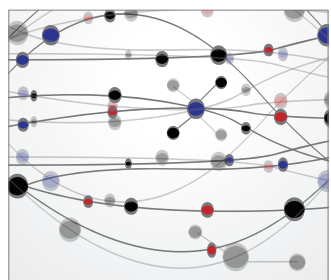

The Scientific World Journal
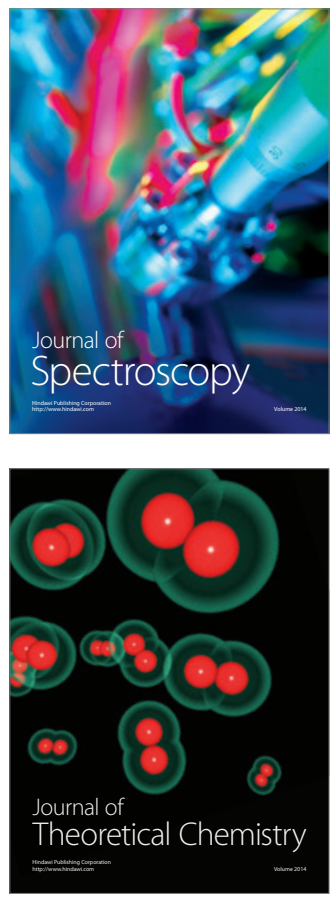
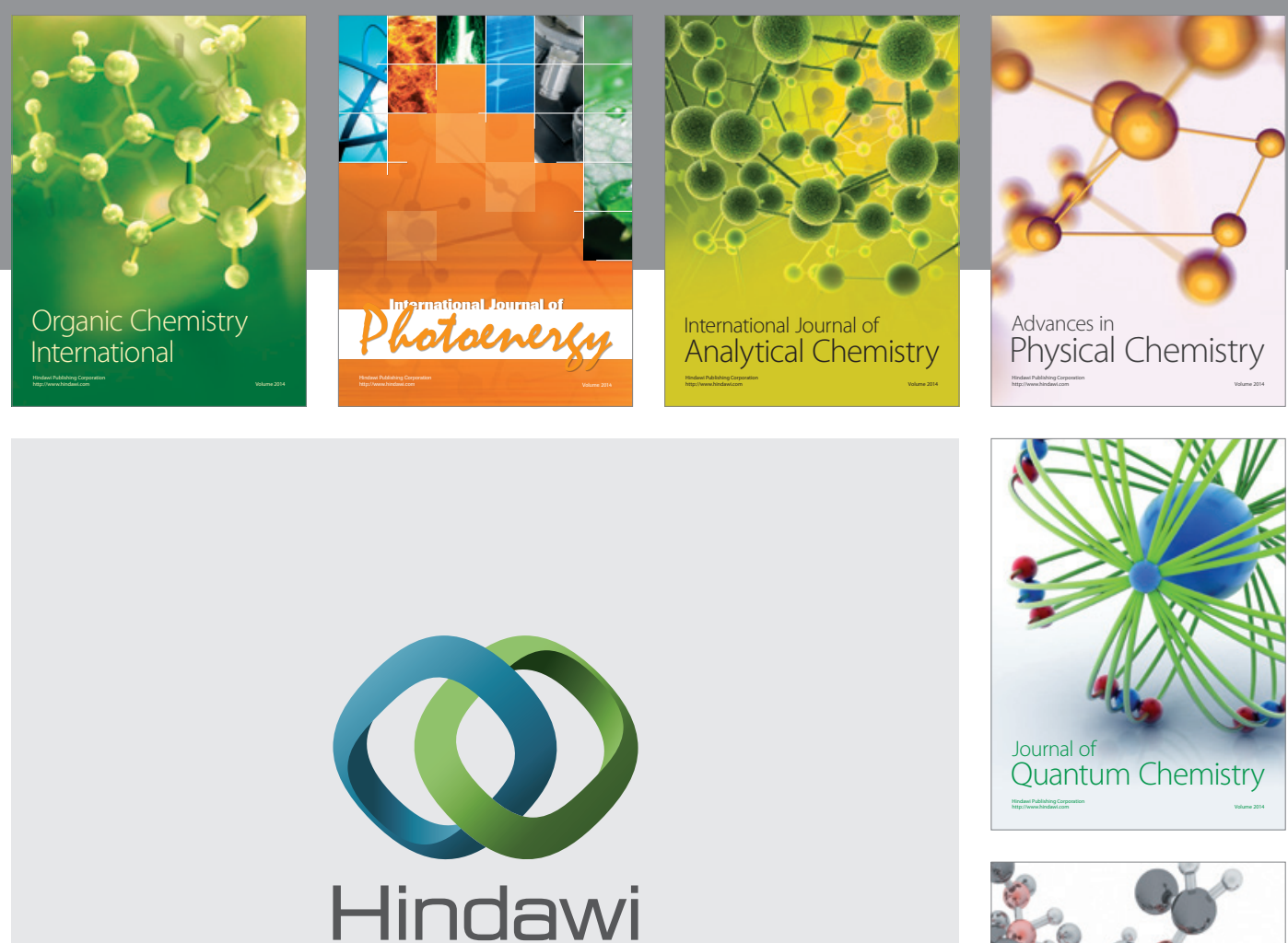

Submit your manuscripts at

http://www.hindawi.com

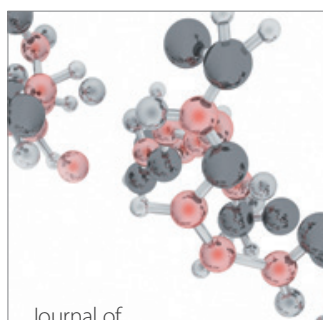

Analytical Methods

in Chemistry

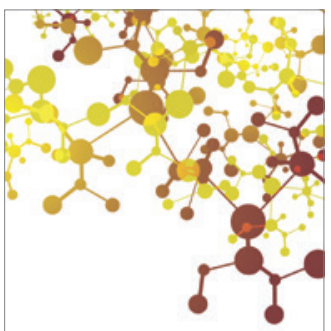

Journal of

Applied Chemistry

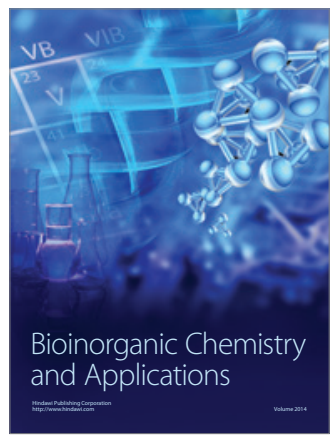

Inorganic Chemistry
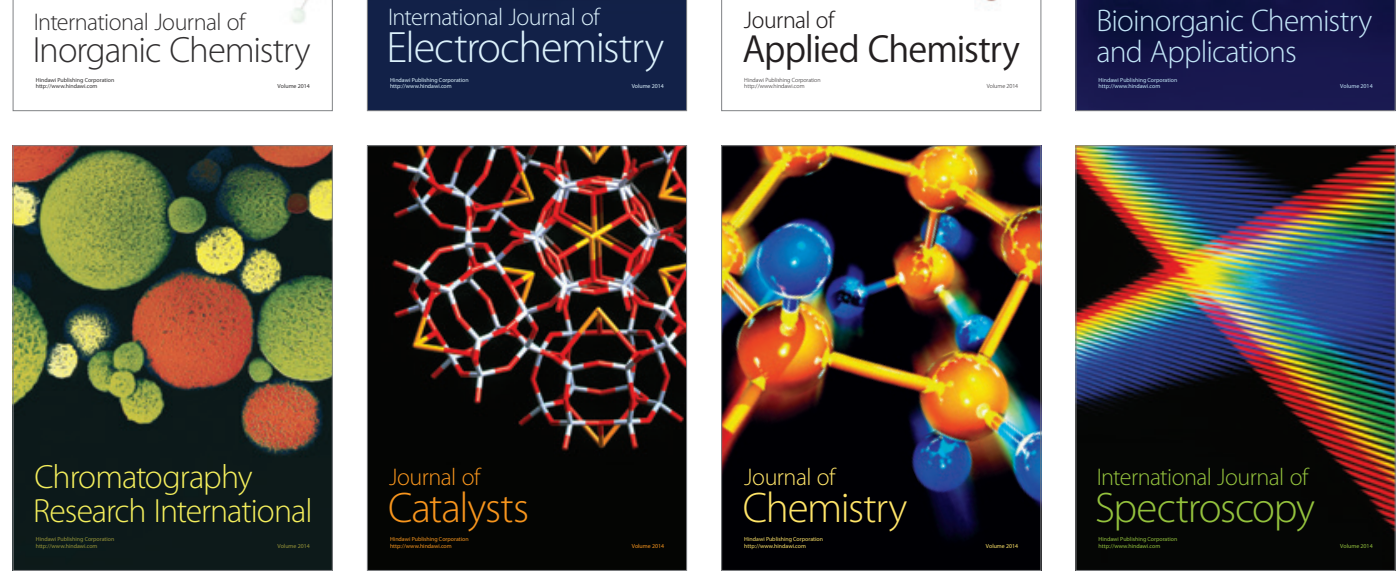